\title{
Suggestions toward quality improvement in public transportation service in Rio Branco, Acre, Brazil
}

\author{
D. I. De Souza ${ }^{1,2}$, D. Kipper ${ }^{1} \&$ P. Duarte ${ }^{1}$ \\ ${ }^{1}$ Civil Engineering Department, Fluminense Federal University, Brazil \\ ${ }^{2}$ Industrial Engineering Department, North Fluminense State University, \\ Brazil
}

\begin{abstract}
The main objective of this work is to analyze the quality of service of the bus companies operating in the city of Rio Branco, located in the state of Acre. This analysis, based on the opinion of the bus users, will determine their degree of satisfaction with the service available. The outcome of this evaluation shows that the users are unhappy with the quality of the service provided by the bus companies and there is a need to identify alternative solutions that may minimize the consequences caused by the main problems detected in this work. With these alternatives available, the bus companies will be able to better understand the needs of their customers in terms of manpower, service cost, time schedule, etc.

Keywords: public transportation, bus companies, quality of service, alternative solutions, passengers' opinion.
\end{abstract}

\section{Introduction}

In Rio Branco, as well as in several other Brazilian cities, there is a need to provide public transportation (mainly buses) to a large number of people, primarily, to those living in the suburbs of the city. The outlying suburbs are essentially caused by the chaotic growth of cities, and, thus, there exists a need for low cost improvement of existing public transportation systems, with the necessary flexibility to adjust the implementation of new lines to the need of potential customers. In the current context, public transportation by bus represents more than $50 \%$ of trips by motorized vehicles in Brazilian cities 
(Pamplona [1]). In spite of this figure, a situation observed since the 1990s, there has been a significant decrease in the demand for public transportation using buses in Brazilian cities. This decrease is caused mainly by the neglect shown by bus companies in relation to their customer's needs; such as comfort, fares, cleanliness, etc. (Raia Jr [2]). The only concern demonstrated by the bus companies is related to the expected short-term profit.

This consumer neglect raises the level of disappointment in bus users; the bus companies do not realize that in order to reach their own primary objective (profitability), they must fulfill at least part of the expectations of their customers. Instead of fulfilling the needs of their customers, the bus companies treat them as "captive customers" knowing that their low incomes will exclude private transport and the people will, of necessity, use the bus. These companies are forgetting that today there are alternative transportation systems (legal or illegal). According to the Brazilian Transportation Office (DETRAN/AC 01/2009), in the state of Acre for each group of six people there is one corresponding motorized vehicle.

The objective of this work is to suggest solutions to minimize the consequences of the main problems related to riders' dissatisfaction identified in our analysis and to help the bus companies operating in Rio Branco better fulfill their customers' needs. This is the only possible way the bus companies will have to survive the competition of alternative transportation systems.

\section{The crisis in the collective transportation system}

The volume of paying passengers has been falling year after year; the low fares have caused a continuous decrease in the profit of the transportation companies. This can be seen in Figure 1 below.

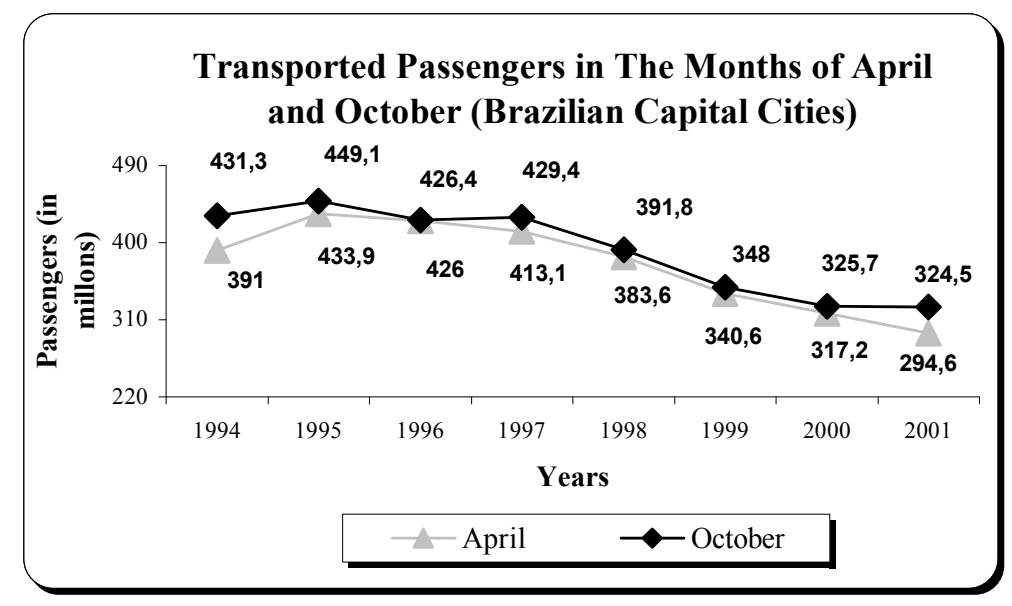

Figure 1: Number of transported passengers during the months of April and October - 1994-2001. 
As major competitors to the bus companies, we have:

- Personal car: The economic stabilization is keeping fuel prices accessible, stimulating some users of public transportation to acquire their own car. To them, the perceived cost is restricted only to fuel expense.

- Informal transportation and alternative transportation: This type of transport has grown rapidly, mainly in 1997 and the beginning of 1998 and now represents $2 \%$ to $5 \%$ of the whole demand for urban transportation in a large number of cities. In some cases, this participation can go up to $10 \%$ (NTU, 1998).

- $\quad$ Motorcycle-taxi: The fare charged is somewhere between the price of a taxi and of a bus. This form of transportation captured an impressive part of the market among users who don't have a personal car, but have an income high enough to use this type of service, which is faster than a bus.

- Travel by foot and by bicycle: This type of travel is common mainly among families having a low income. The number of trips made on foot has been growing rapidly since 1992, according to Brasil [3]: "In the last 10 years, the percentage of people that travels by foot has grown from $20 \%$ to $25 \%$ to levels up to $50 \%$. With relation to travel by bicycle, it is estimated that there are around 45 million bicycles operating in the country".

- $\quad$ Private Bus: Initially, these were utilized as school transportation, but today are also used in the transportation of people from residential areas to working places and back.

\section{Methodology}

The research method used in this work was basically exploratory and the work in question consists of a case study performed for the bus companies in the city of Rio Branco, located in the state of Acre. In this study, the population was defined as being external clients, the customers of the bus companies. A random sample of 250 users was randomly selected among all the 35 existing bus lines. This research was performed in 2009 during the months of June and July. Table 1 below shows the bus companies' user population and sample data.

A questionnaire or survey, with 21 questions and space for suggestions was used to collect information from the customers. The questionnaire is presented in the Appendix.

The research survey was divided into four parts:

1. Questions referring to the users' profile;

2. Questions referring to several conditions (attributes);

Table 1: $\quad$ Bus companies' user population and sample data.

\begin{tabular}{l|l|}
\hline \multicolumn{1}{|c|}{ Population } & \multicolumn{1}{|c|}{ Sample } \\
\hline $\begin{array}{l}\text { Average of 2,439,229. passengers/month, } \\
\text { corresponding to about 55,437.02 passengers/day }\end{array}$ & from the existing \\
(considering that all of them travel 22 days per month, & bus companies $\approx$ \\
twice a day, outbound and inbound). & $0.45 \%$
\end{tabular}


3. Questions referring to trip characteristics;

4. Suggestions.

These questions relating to several conditions had the objective of analyzing the users' satisfaction with the time elapsed inside the bus during the trip; the number of buses available in a particular bus line; the interval between buses; comfort; cleanliness; conservation; safety; noise and air pollution; fare; schedule and employees' courtesy. Finally, using a frequency distribution approach, the data collected was quantitatively analyzed.

\section{Analysis of the results}

Table 2 in the next page shows the results obtained from this survey. From Table 2 we can see that the level of service offered by the bus companies was considered average and bad by the majority of the users. Only the attributes related to the itinerary of the buses, employees' courtesy, safety, time spent during trip inside the bus and scheduling received more than $20 \%$ of a "good" evaluation. The suggestions proposed in this work would be the ones related to the attributes that received the worst evaluation by the customers.

\section{Quality level}

Table 3 shows the evaluation results (number of customers per item).

Table 2: Questionnaire results for this survey.

\begin{tabular}{|c|c|c|c|}
\hline \multirow{2}{*}{ Conditions } & \multicolumn{3}{|c|}{ Bus Companies } \\
\cline { 2 - 4 } & \multicolumn{3}{|c|}{ Evaluation (\%) } \\
\cline { 2 - 4 } & Good & Average & Bad \\
\hline Time spent during trip inside the bus & 23 & 35.1 & 41.9 \\
\hline Bus itinerary & 30.4 & 36.4 & 33.2 \\
\hline Interval between buses & 11.5 & 16.8 & 71.7 \\
\hline Number of buses in the lines & 14.3 & 26.8 & 58.9 \\
\hline Cleanness & 15.3 & 43.3 & 41.4 \\
\hline Conservation & 10.2 & 42.9 & 46.9 \\
\hline Comfort & 5.2 & 20.4 & 74.4 \\
\hline Safety & 23.2 & 28.0 & 48.8 \\
\hline Noise and air pollution & 6.8 & 30.9 & 62.3 \\
\hline Fare & 13.0 & 25.5 & 61.5 \\
\hline Schedule & 22.6 & 32.5 & 44.9 \\
\hline Employees' courtesy & 28.7 & 52.6 & 18.7 \\
\hline
\end{tabular}


Table 3: Questionnaire results for this survey (customers per item).

\begin{tabular}{|c|c|c|c|}
\hline \multirow{2}{*}{ Conditions } & \multicolumn{3}{|c|}{ Bus Companies } \\
\cline { 2 - 4 } & \multicolumn{2}{|c|}{ Evaluation (250 Customers per item) } \\
\cline { 2 - 4 } & Good & Average & Bad \\
\hline Time spent during trip inside the bus & 57 & 88 & 105 \\
\hline Bus itinerary & 76 & 91 & 83 \\
\hline Interval between buses & 29 & 42 & 179 \\
\hline Number of buses in the lines & 36 & 67 & 147 \\
\hline Cleanness & 38 & 108 & 104 \\
\hline Conservation & 26 & 107 & 117 \\
\hline Comfort & 13 & 51 & 186 \\
\hline Safety & 58 & 70 & 122 \\
\hline Noise and air pollution & 17 & 77 & 156 \\
\hline Fare & 33 & 64 & 153 \\
\hline Schedule & 57 & 81 & 112 \\
\hline Employees' courtesy & 72 & 132 & 46 \\
\hline Total & 512 & 978 & 1510 \\
\hline
\end{tabular}

Using the results obtained from Table 3 it is possible to determine the overall quality level of the service provided by the bus companies in the city of Rio Branco. These results could be used in the future to evaluate whether the researched bus companies have improved their service and fulfilled their customers' needs.

To determine the overall quality level the following steps should be followed:

1. Determine the total number of customers that:

a. $\mathrm{S}_{\mathrm{g}}$ Considered the items researched as good;

b. $\mathrm{S}_{\text {ave }}$ : Considered the items researched as average;

c. $\mathrm{S}_{\mathrm{b}}$ : Considered the items researched as bad.

The following weights were used for each of the classifications:

d. Good: $p_{g}=2$;

e. Average: $p_{\text {ave }}=1$;

f. Bad: $\mathrm{p}_{\mathrm{b}}=0$.

2. Multiply the obtained values for each of the classifications by its corresponding weights. As a result we will have the overall quality level (OQL) given by eqn (1):

$$
\mathrm{OQL}=\mathrm{S}_{\mathrm{g}} \times \mathrm{p}_{\mathrm{g}}+\mathrm{S}_{\mathrm{ave}} \times \mathrm{p}_{\mathrm{ave}}+\mathrm{S}_{\mathrm{b}} \times \mathrm{p}_{\mathrm{b}}
$$

Now, with $p_{g}=2, p_{a v e}=1$ and $p_{b}=0$, we will have:

$$
\mathrm{OQL}=2 \mathrm{~S}_{\mathrm{g}}+\mathrm{S}_{\mathrm{ave}}
$$


3. Compare the obtained OQL value with the "maximum theoretical value" that eqn (2) could have, that is, the total number of items multiplied by the number of customers surveyed (in this work, 12 items and 350 customers researched), multiplied by 2 , the corresponding weight for the classification "good." Since in this "optimal theoretical case" all the customers surveyed gave the classification "good" to all the items researched, the value of $\mathrm{S}_{\mathrm{ave}}$ in eqn (2) will be equal to zero. This comparison is given by:

$$
\mathrm{OQL} \leq \mathrm{T}_{\mathrm{V}}=2 \times 12 \times \mathrm{n}
$$

Here, $n$ is the number of customers researched $(250), \mathrm{T}_{\mathrm{V}}$ is the "optimal theoretical value" that eqn (3) could have, 2 is the corresponding weight for the classification "good" and 12 is the number of items surveyed in this work. Then:

$$
\mathrm{T}_{\mathrm{V}}=2 \times 12 \times \mathrm{n}
$$

4. Now, to compare the obtained OQL value with the "maximum theoretical value" that eqn (2) could have, we will use the following classification:

a. The OQL value is located between $90 \%$ and $100 \%$ of the $\mathrm{T}_{\mathrm{V}}$ value: The service level is considered to be "good"; the customers' needs are being fulfilled. The bus company should keep up the good work.

b. The OQL value is located between $70 \%$ and $89 \%$ of the $\mathrm{T}_{\mathrm{V}}$ value: The service level is considered to be "satisfactory". However, the service level should be improved in order to exceed the customers' expectation.

c. The OQL value is located between $40 \%$ and $69 \%$ of the $\mathrm{T}_{\mathrm{V}}$ value: The service level is considered to be "reasonable", but there are complaints about some areas of service rendered by the bus company.

d. The OQL value is located between $10 \%$ and $39 \%$ of the $\mathrm{T}_{\mathrm{V}}$ value: The service level is considered to be "bad", and urgent measures should be taken by the bus company in order to continue operating.

e. The OQL value is located below $10 \%$. The service level is considered to be "very bad". The city authorities should immediately consider cancelling the bus company's concession.

\section{The overall quality level for the bus companies}

Using eqn (2), with $\mathrm{S}_{\mathrm{g}}=512, \mathrm{~S}_{\mathrm{ave}}=978$ and $\mathrm{S}_{\mathrm{b}}=1510$, we will have:

$\mathrm{S}=2 \mathrm{~S}_{\mathrm{b}}+\mathrm{S}_{\mathrm{re}}+0 \times \mathrm{S}_{\mathrm{b}}=2 \times 512+978=1024+978$. Then: $\mathrm{S}=2002$

Verifying if $\mathrm{S} \leq \mathrm{T}_{\mathrm{V}}$ :

$\mathrm{T}_{\mathrm{V}}=2 \times 12 \times \mathrm{n}=2 \times 12 \times 250=6000$. As a result, $\mathrm{S} \leq \mathrm{T}_{\mathrm{V}}$, since $2002 \leq 6000$.

Therefore: $\mathrm{S}=2002$, which represents $33.4 \%$ of $\mathrm{T}_{\mathrm{V}}$. 
This overall quality level (OQL) value of $33.4 \%$ is located between $10 \%$ and $39 \%$ of the $T_{V}$ value. The service level is considered to be "bad", and urgent measures should be taken by the bus companies in order to raise their level of service.

\section{Possible suggestions}

The analysis of the survey answered by the bus companies' customers have shown that all the conditions considered in the questionnaire need to be improved, especially the ones related to comfort, interval between buses, noise and air pollution, fare and number of buses in the line.

Some of the problems found in this study will demand time and money to be solved or at least, eased. The major challenge the bus companies will face is to determine among the analyzed conditions, which ones should be improved in the nearby future by the bus company itself, and which ones will need to have help of the city government to be improved.

The conditions that were given a bad evaluation greater than $50 \%$ were:

- Comfort;

- Interval between buses;

- Noise and air pollution;

- Fare;

- Number of buses in the line.

The suggestions for improvement for these conditions are shown in Table 4. It can be also seen that in some cases the implantation of one suggestion could help in the solution of more than one problem.

\section{Conclusions}

The bus companies located in Rio Branco need to go through a process of "change of attitude" in order to improve the quality of their offered services. The poor quality they offer can be confirmed by the great dissatisfaction reported by their users, since most of their users considered seven of the twelve conditions analyzed "bad" (above 45\%). The overall quality level (OQL) value of 33.4\% obtained by the bus companies is located between $10 \%$ and $39 \%$ of the optimal theoretical value $\left(\mathrm{T}_{\mathrm{V}}\right)$ that this OQL equation could have. The service level was considered to be "bad", and urgent measures should be taken by the bus companies in order to raise their level of service.

It must be understood that most of the bus companies' customers are young people, mainly university students and technical personnel. Those people usually are more demanding and, perhaps, the result of the survey applied in this study would be a little more favorable to the bus company if their customers were people without a higher education. 
Table 4: Suggestions, objectives, problems to be solved, time of implantation and costs for the main problems found in this survey.

\begin{tabular}{|c|c|c|c|c|}
\hline Suggestion & Objective & $\begin{array}{c}\text { Problem to be } \\
\text { solved }\end{array}$ & $\begin{array}{l}\text { Time of } \\
\text { implantation }\end{array}$ & Cost \\
\hline $\begin{array}{l}\text { Install a } \\
\text { Consumer } \\
\text { Service } \\
\text { Center } \\
\text { (CSC) }\end{array}$ & $\begin{array}{l}\text { To hear the } \\
\text { opinion of the } \\
\text { user, verifying } \\
\text { what their real } \\
\text { needs are. }\end{array}$ & $\begin{array}{l}\text { Companies don't } \\
\text { know the needs } \\
\text { of their users }\end{array}$ & Short/Medium & $\begin{array}{l}\text { Low/ } \\
\text { Medium }\end{array}$ \\
\hline $\begin{array}{l}\text { Renew, } \\
\text { Increase and } \\
\text { Maintain the } \\
\text { Fleet }\end{array}$ & $\begin{array}{l}\text { To improve the } \\
\text { conditions of the } \\
\text { buses, } \\
\text { substituting the } \\
\text { ones that have } \\
\text { already exceeded } \\
\text { their useful life } \\
\text { time and to } \\
\text { increase the fleet } \\
\text { diminishing the } \\
\text { interval between } \\
\text { buses and the } \\
\text { waiting time }\end{array}$ & $\begin{array}{l}\text { Lengthy intervals } \\
\text { between buses } \\
\text { and long wait } \\
\text { time, insufficient } \\
\text { number of buses, } \\
\text { lack of } \\
\text { conservation, } \\
\text { comfort and of } \\
\text { security, great } \\
\text { amount of noise } \\
\text { and air pollution } \\
\text { and lack of } \\
\text { regular } \\
\text { scheduling }\end{array}$ & $\begin{array}{l}\text { Medium } \\
\text { /Long }\end{array}$ & High \\
\hline Fare & $\begin{array}{l}\text { To improve the } \\
\text { welfare of the } \\
\text { user }\end{array}$ & $\begin{array}{l}\text { Lack of a better } \\
\text { fare system }\end{array}$ & Short & Low \\
\hline $\begin{array}{c}\text { Better } \\
\text { Scheduling } \\
\text { and Planning } \\
\text { to Diminish } \\
\text { Intervals } \\
\text { Between } \\
\text { Buses }\end{array}$ & $\begin{array}{l}\text { To make the } \\
\text { schedules of the } \\
\text { buses more } \\
\text { regular and the } \\
\text { intervals between } \\
\text { them diminish }\end{array}$ & $\begin{array}{l}\text { Long intervals } \\
\text { between buses, } \\
\text { lack of regular } \\
\text { scheduling, } \\
\text { extensive time of } \\
\text { wait }\end{array}$ & Short/Medium & $\begin{array}{l}\text { Low/ } \\
\text { Medium }\end{array}$ \\
\hline $\begin{array}{l}\text { Inform the } \\
\text { Users }\end{array}$ & $\begin{array}{l}\text { To maintain the } \\
\text { user informed } \\
\text { about the bus } \\
\text { companies }\end{array}$ & $\begin{array}{l}\text { Misinformed } \\
\text { users, long } \\
\text { waiting time }\end{array}$ & Short & Low \\
\hline $\begin{array}{l}\text { Utilize } \\
\text { Alternative } \\
\text { Fuels }\end{array}$ & $\begin{array}{l}\text { To diminish the } \\
\text { effects of noise } \\
\text { and pollution of } \\
\text { air generated by } \\
\text { the bus }\end{array}$ & $\begin{array}{l}\text { Great generation } \\
\text { of noise and air } \\
\text { pollution }\end{array}$ & Long & High \\
\hline
\end{tabular}


We have to remember that this survey was performed while the users were waiting for the bus in a certain location and during a certain time period and the combination of these two factors could have guided the users to answer the questions in a more "severe" way.

As we have mentioned before, the major challenge the bus companies will face is to determine among the analyzed conditions, which ones they should improve in the nearby future, and which ones will need the help of the city government to be improved.

\section{Appendix. Questionnaire related to customers' opinion - quality of public transportation: buses}

\section{Part 1: Users' profile}

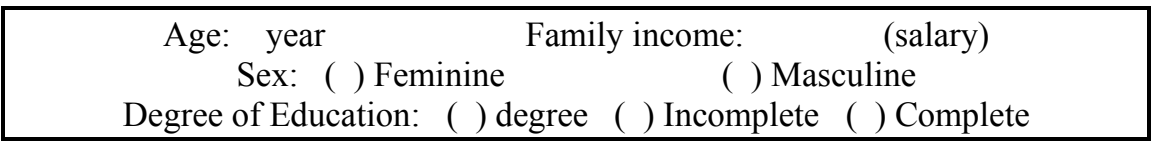

Part 2: Several conditions

(Mark with a $\mathrm{X}$ the rating you consider the most adequate)

\begin{tabular}{|c|c|c|c|}
\hline \multirow{2}{*}{ Conditions } & \multicolumn{3}{|c|}{ Bus Companies } \\
\cline { 2 - 4 } & \multicolumn{2}{|c|}{ Evaluation (\%) } \\
\cline { 2 - 4 } & Good & Average & Bad \\
\hline Time spent during trip inside the bus & & & \\
\hline Bus itinerary & & & \\
\hline Interval between buses & & & \\
\hline Number of buses in the lines & & & \\
\hline Cleanness & & & \\
\hline Conservation & & & \\
\hline Comfort & & & \\
\hline Safety & & & \\
\hline Noise and air pollution & & & \\
\hline Fare & & & \\
\hline Schedule & & & \\
\hline Employees' courtesy & & & \\
\hline
\end{tabular}


Part 3: Trip characteristics

Reason for this trip? ( ) Study ( ) Work ( ) Shopping ( ) Other

When you travel, you:

( ) Utilize buss pass ( ) Pay full fare ( R \$ 0,90)

( ) Utilize scholar pass ( ) Have free pass

What is the daily average time that you spend in transport, considering wait and trip time?

( ) Between 15 and $30 \mathrm{~min}$.

( ) Between 30 and $45 \mathrm{~min}$.

( ) Between $45 \mathrm{~min}$. and $1 \mathrm{~h}$.

( ) Between 1h. and 1:15 min

( ) Between 1:15 min. and 1:30 min.

( ) More than $1 \mathrm{~h}$ and $30 \mathrm{~min}$.

In your opinion, which are the more critical days and schedules?

More critical days:

More critical schedules:

( ) Weekdays (Monday to Friday) ( ) During the day (between 5 and $18 \mathrm{~h}$.)

( ) Weekends and holidays ( ) Night (between 18 and 24h)

How often do you utilize public transportation?

( ) Daily ( ) According to necessity

( ) Once a week

( ) Twice or three times a week

\section{References}

[1] Pamplona, M. R. Consideration about the use of different types of buses in the urban transportation system (in Portuguese). Master dissertation paper, 2000, São Carlos Engineering University, São Carlos, Brazil.

[2] Raia Jr., A. A. Users' opinion about the quality of service of the bus companies operating in the city of São Carlos (in Portuguese). Transportation and Transit National Congress, 12 pages, Recife, Brazil, 1999.

[3] Brasil A. Personal Communication, 2002, Urban Transport Secretary, Brazilian Government, Brasília, Brazil. 